\title{
Scaffolding of small groups' metacognitive activities with an avatar
}

\author{
Inge Molenaar • Ming Ming Chiu • Peter Sleegers • \\ Carla van Boxtel
}

Received: 14 March 2011 / Accepted: 30 August 2011 /

Published online: 12 October 2011

(C) The Author(s) 2011. This article is published with open access at Springerlink.com

\begin{abstract}
Metacognitive scaffolding in a computer-supported learning environment can influence students' metacognitive activities, metacognitive knowledge and domain knowledge. In this study we analyze how metacognitive activities mediate the relationships between different avatar scaffolds on students' learning. Multivariate, multilevel analysis of the 51,339 conversation turns by 54 elementary school students working in triads showed that scaffolding has an effect on students' learning. Students receiving structuring or problematizing metacognitive scaffolds displayed more metacognitive knowledge than students in the control group. Metacognitive activities mediated the effects of scaffolding, and increased metacognitive activities supported students' metacognitive knowledge. Moreover, students who were engaged in proportionately more cognitive activities or fewer off-task activities also outperformed other students on the metacognitive knowledge test. Only problematizing scaffolds led to more domain knowledge and metacognitive activities mediated the effects of the problematizing scaffolds. Moreover, students in the problematizing condition who engaged in more cognitive activities or whose group mates used more relational activities had greater domain knowledge acquisition than other students.
\end{abstract}

Keywords Scaffolding $\cdot$ Metacognition $\cdot$ Embodied agents $\cdot$ Elementary education

I. Molenaar $(\bowtie) \cdot$ C. van Boxtel

Department of Child Development and Education, University of Amsterdam, Postbus 94208, 1090 GE Amsterdam, the Netherlands

e-mail: i.molenaar@uva.nl

M. M. Chiu

Department of Learning and Instruction, State University of New York-Buffalo, Buffalo, USA

P. Sleegers

Department of Education Organization and Management, University of Twente, Enchede, the Netherlands 


\section{Introduction}

Students collaborating in computer-based learning environments often have problems regulating their learning (Azevedo and Hadwin 2005; Manlove et al. 2006). They often do not engage in enough metacognitive activities to control and monitor their learning. Metacognitive scaffolding can support students' metacognitive activities and learning (Azevedo et al. 2008; Land and Green 2000; Veenman et al. 2005). However previous scaffolding studies only examined the effects of scaffolding on students' learning (Molenaar et al. 2010; Veenman 2011). Therefore, there is little in-depth knowledge of how metacognitive activities are related to types of scaffolding (structuring vs. problematizing) and learning. Unlike past studies on a data set that examined whether the post-intervention outcomes or the group's metacognitive activities simply differ across the control and experimental conditions (Molenaar et al. in press), this study uses multivariate, multilevel methods on a subset of the data to test an explanatory model of the relationships among the scaffolds, student activities (metacognitive and others), group mate activities, and individual learning.

Moreover, most research into scaffolding focuses on the effects of metacognitive scaffolds in individual settings (Azevedo et al. 2008; Veenman et al 2005). Although these results can be used to understand the role of metacognitive scaffolding on student learning in collaborative learning settings, some important issues related to the nature of collaborative learning need further exploration. In small groups, students elaborate, discuss and give feedback on one another's contributions, which supports learning (Chi 2009; Van Boxtel 2004; Van Drie and Van Boxtel 2004; Webb 2009). Furthermore, student involvement is important, a student's constructive activities affect learning more than active activities attending to other student's contributions (Chi 2009). Consequently, to understand the effect of scaffolding in collaborative settings, it is crucial to understand how scaffolds influence student involvement embedded in the group's interaction. In addition, the underlying assumption of constructivist theories is that the nature of learning activities (e.g. cognitive, metacognitive activities) influences student learning (Duffy and Jonassen 1992; Janssen et al. 2010). During collaborative learning, many activities beyond metacognitive activities (such as cognitive, relational and off-task activities) support students' learning (Janssen et al. 2010). Therefore, we will argue that a comprehensive analysis of how metacognitive scaffolding affects learning requires that the other learning activities are taken into account to assess the unique effects of metacognitive activities.

This paper examines the question: to what extent do metacognitive activities mediate the effects of different scaffolds on students' learning? We argue that different forms of metacognitive scaffolds foster metacognitive activities differently and, in turn, will have differential effects on student learning, i.e., students' metacognitive knowledge and domain knowledge. We expect that metacognitive activities mediate this relationship between scaffolding and individual learning. The activities of 54 students during their 51,339 conversation turns across 108 hours analyzed as they collaborated face-to-face in triads in a computer supported learning environment. There were three metacognitive scaffolding conditions (none, structuring, and problematizing). We used mixed methods, namely discourse analysis and multi-level statistical analysis. As such, this paper not only contributes to our understanding of how different metacognitive scaffolds affect students' metacognitive activities and learning, it also offers practical insights on how to create scaffolds that support students' engagement in activities that aid learning. 


\section{The effect of metacognitive scaffolding on metacognitive activities and learning}

Scaffolding is defined as providing assistance to a student when needed and fading the assistance as the competence of the student increases (Wood et al. 1976). Research indicates that scaffolding facilitates learning as it supports learners in tasks that they cannot accomplish successfully by themselves, as well as developing knowledge for future learning (Hmelo-Silver and Azevedo 2006; Pea 2004; Sharma and Hannafin 2007). Metacognition is defined as knowledge about and regulation of cognitive activities (Flavell 1979). Metacognitive scaffolding aims to help students to adequately control and monitor their learning (Azevedo et al. 2008; Molenaar et al. 2010; Veenman et al. 2005). Students in small groups are supported to engage in metacognitive activities, such as orientation, planning, monitoring, evaluation and reflection (Meijer et al. 2006). Research showed that metacognitive scaffolds in small groups stimulates metacognitive activities and enhances students' learning (Azevedo and Cromley 2004; Land and Green 2000). Researchers often assume that metacognitive activities mediated the effect of scaffolding on learning, but there is little empirical evidence for this assumption (Veenman et al. 2005). Moreover, scaffolding and metacognitive activities are often embedded in interaction among the group members. To understand how metacognitive scaffolding affects students' learning during collaboration, we look at perspectives on collaborative learning.

Collaboration can aid student learning when students modify their knowledge through interactions within their group. Various collaborative learning perspectives e.g., cognitive elaboration, Chi 2009; Mercer 1996; Webb 2009; van Boxtel 2004; socio-cognitive conflict, Piaget 1932; Doise 1990; Doise and Mugny 1984; co-construction, Hatano 1993; van Boxtel 2004) stress different mechanisms that cause learning during collaboration (giving, receiving and using explanations; resolving conflicts; co-construction). They all emphasize that students' elaborations on one another's contributions support learning. Thus, a side effect of metacognitive scaffolding in small groups is that the interaction among the group members can stimulate reflection, provide feedback and elicit discussion of metacognitive activities, which in turn enhances individual learning (Chi 2009; Webb 2009).

Another important issue influencing learning in collaborative settings is a student's involvement in the learning activities. Active vs. constructive vs. interactive learning activities are each related to different cognitive processes (Chi 2009). Active activities entail attending to ongoing actions through activating prior knowledge, assimilating new knowledge and storing it (Chi 2009). Stronger involvement is found in constructive activities, in which a student goes beyond the presented information through self-explaining, inferring new knowledge, and organizing or restructuring existing knowledge (Mayer \& Wittrock, 1996; Chi 2009). Finally, in interactive activities, students build on their group members' contributions through elaboration, feedback, agreeing and challenging ideas (Chi 2009; Webb 2009). For example, studies have shown that even collaboration with an ignorant partner generates better learning achievements than learning alone (Chi 2009). Ignorant partners pose questions that elicited their partner's constructive activity. Furthermore, in pairs of students with similar past achievement, in which each student performs as an "explainer" or a "listener" role, the explainers learn more than the listeners (Coleman et al. 1997; Hausmann et al. 2004; Schwartz and Bransford 1998). By engaging in more constructive activities than the listeners, the explainers benefit more from their participation in collaborative activity. This indicates that even though interaction among group members supports learning during collaboration, the student's involvement in these activities influences how he or she learns. Thus, students who engage in more constructive activities due to scaffolding might benefit more than students who engage only in active activities. 
Based on the above research, it can be argued that scaffolding in a collaborative setting may foster student involvement embedded in interaction among the group members, which in turn, affects students' learning. Reiser (2004) specified two mechanisms to explain how scaffolding affects student learning. Structuring simplifies the learning assignment by reducing its complexity, clarifying the underlying components and supporting performance (i.e., providing the students with an example of a plan for the assignment). Problematizing increases the complexity of the learning assignment by emphasizing certain aspects of the assignment and asking learners to clarify the underlying components and perform actions to construct their own strategies (i.e., asking students to make their own plan for the assignment). These different mechanisms support the formation of different scaffolds that either structure or problematize metacognitive aspects of the learning assignment.

Structuring scaffolds give context suitable examples of metacognitive activities to the group (e.g., showing students an exemplary plan for their mind mapping task when they start this task "What would you like to learn; let's make a mind map with important topics to learn, for instance the climate"). Structuring scaffolds encourage students' attention to the information in the scaffold, but do not invite them to construct their own metacognitive activities. On the other hand, problematizing scaffolds pose context suitable questions that elicit students' metacognitive activities (e.g., asking students to plan their mind mapping task when they start this task "How are you going to make the mind map?"). Past studies showed that problematizing scaffolds such as question prompts elicit students' explanations and support articulation of students' thinking (Chi et al. 2001; Davis and Linn 2000; King 1998, 2002). Thus, problematizing scaffolds are likely to encourage students' constructive activities.

Different scaffolds could influence student involvement differently. Scaffolds that drive the students' interaction could stimulate metacognitive activities beyond the direct impact of the scaffolding. Interaction among the group members can further stimulate metacognitive activities when students start to elaborate, discuss and reflect on one another's contributions. Referring back to the example of the structuring planning scaffold, students can elaborate on this example, adjusting and shaping the group's plan for the mind map task. In response to the problematizing scaffolds, students can have discussions about (conflicting) views, exchange, share, or co-construct metacognitive activities together.

To conclude, metacognitive scaffolding can influence student learning through supporting and stimulating metacognitive activities that monitor and control the group's cognitive activities. Different scaffolds provide different supports for metacognitive activities, possibly stimulating student involvement embedded in the interaction between the group members differently. Unlike scaffolding in an individual setting, student interaction scaffolding in a collaborative setting modifies student involvement and supports additional metacognitive activities which can influence learning. The next section elaborates on the effect of metacognitive activities on learning in collaborative settings.

\section{Effects of metacognitive activities on learning during collaboration}

In the section above, we argued that metacognitive scaffolding can stimulate metacognitive activities, which in turn aids student learning of domain and metacognitive knowledge (Veenman 2005; 2011). Metacognitive activities monitor and control cognitive activities, which directly address the task content; for example, students read, elaborate and process information in discussions. Students who engage in more cognitive activities acquire more domain knowledge (Chinn et al. 2000; Howe et al 2007). Metacognitive activities support the development of domain knowledge through activating prior knowledge, planning the 
use of effective strategies to obtain learning goals, integrating new knowledge with existing knowledge, monitoring the group's activities in relation to the learning goals, and evaluating understanding. Such metacognitive activities optimize the cognitive activities, which aids student learning of domain knowledge.

Metacognitive activities support student's metacognitive knowledge through showing examples, providing room for practice and receiving feedback (Veenman 2011). Group members construct metacognitive activities in reciprocal interaction (Iiskala et al. 2004; Iiskala et al. 2010). Moreover, metacognitive activities embedded in intensive interaction among the group members support productive metacognitive decisions (Goos et al. 2002). These interactions are likely to also help develop students' metacognitive knowledge (Salomon 1993; Veenman 2011; Molenaar et al. in press). Students in groups can share existing metacognitive knowledge and build on one another's metacognitive contributions to co-construct new metacognitive knowledge (Lin and Sullivan 2008; Iiskala et al. 2010). Their metacognitive activities can elicit new activities from the other group members. These activities offer opportunities for further metacognitive activities and allow students to appropriate knowledge from other group members. Subsequently, these activities can aid students' developing knowledge and alter their future participation, which in turn can contribute to the knowledge development of other group members (Salomon 1993; Volet et al. 2009). As noted above, student involvement varies across activities (Chi 2009). Students' own activities are often constructive; whereas attending to other group members' contributions often only requires their attention (Chi 2009). Thus we argue that a student's own metacognitive activities are more likely than attention to other group members' metacognitive activities to influence his or her metacognitive knowledge.

Apart from cognitive and metacognitive activities in the problem content space, students in small groups engage in activities in the social relational space (i.e., motivating one another, engaging one another and managing allocation of tasks; Janssen et al. 2010; McGrath 1991). The group's activities in the relational space can enhance group members' social relationships, aid their collaboration and facilitate their learning. These relational activities foster a positive group climate, increase group cohesion, and aid task completion (Kreijns et al. 2003; Massey et al 2003; McGrath 1991; Jehn and Shah 1997; Wilson et al. 2006). Likewise, negative socio-emotional processes such as rudeness, insults or domination reduce the quality of group solutions (Chiu and Khoo 2003; Webb et al. 2002). Off-task activities (e.g., discussing weekend plans) in the social relational space can improve relationships among group members, but they also tend to reduce learning and achievement (Chiu 2004). Accordingly, cognitive activities and metacognitive activities support the development of knowledge, while relational activities foster a positive group climate that can support learning. In contrast, offtask behaviors often hinder learning. Hence, multiple activities must be modeled when analyzing the effects of scaffolding and metacognitive activities on learning.

\section{The present study}

The purpose of this study is to examine the relationships among different scaffolds, metacognitive activities and students' learning in a collaborative learning setting. To our knowledge, there are few empirical studies available on the effects of scaffolding on learning in a group setting that also accounts for both the learning activities and the learning outcomes. We report an experiment with three metacognitive scaffolding conditions (none, structuring, and problematizing). The main question addressed in this study is: To what extent do metacognitive activities mediate the effects of metacognitive scaffolding and 
different scaffolds (structuring vs. problematizing) on students' domain and metacognitive knowledge? This question entails three hypotheses:

Hypothesis 1. Scaffolding and different scaffolds support student' domain and metacognitive knowledge

Previous studies have shown that scaffolding improves student learning. Therefore, we expect that students supported by scaffolding will outperform students in the control group on both domain and metacognitive knowledge. As problematizing scaffolds are more likely than structuring scaffolds to foster constructive metacognitive activities, we expect students supported with problematizing scaffolds to outperform those supported with structuring scaffolds on both domain and metacognitive knowledge.

Hypothesis 2 Scaffolding and different scaffolds support metacognitive activities

Previous studies have shown that scaffolding stimulates metacognitive activities. Thus, we expect more metacognitive activities from students receiving scaffolding than those who do not. As problematizing scaffolds explicitly elicit students' metacognitive activities and stimulate interaction among students, we expect more metacognitive activities from students who receive problematizing scaffolds than those who receive structuring scaffolds.

Hypothesis 3. Metacognitive activities support student' domain and metacognitive knowledge

Finally, we argued that metacognitive activities support students' domain knowledge and metacognitive knowledge. As outlined above, student involvement in learning activities influences their learning. A student's own activities are likely to aid learning more as they are often more constructive than simply attending to other group members' contributions. Therefore, we expect that a student's own metacognitive activities are more important than group members' metacognitive activities in mediating the relationship between metacognitive scaffolding and individual learning.

Figure 1 shows a path diagram of the hypothesized relationships.

\section{Methods}

Subjects

For this study, we analyzed the learning activities of students. Due to the laborintensive nature of discourse analysis, we could not analyze all triads that participated

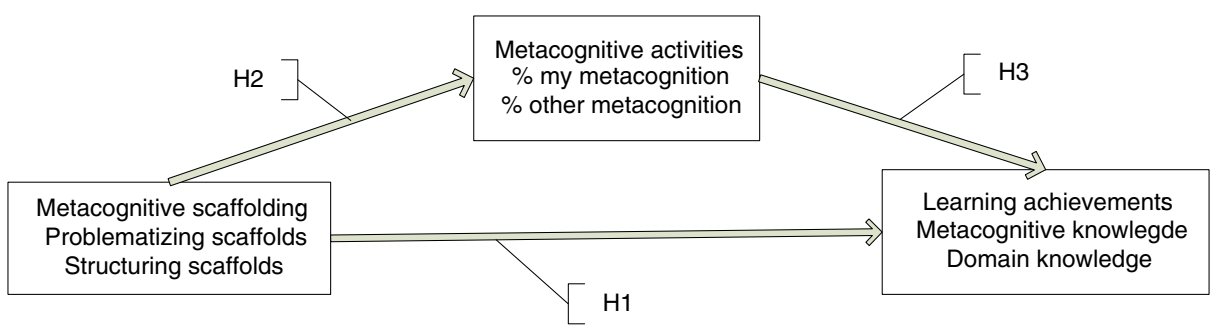

Fig. 1 Overview of the relations studied 
in the full study (Molenaar et al. 2010). In the full study, 156 students in three schools divided over six classes participated. The teachers assigned students to triads (52) to maximize heterogeneity. Teachers rated students as low, middle or high achievers based on their reading, writing and computer abilities and then created triads containing one low, one middle and one high achiever, with at least one boy and one girl. We randomly assigned the triads to the three experimental conditions: (a) no scaffolds (control group, 16 triads); (b) structuring scaffolds (experimental group 1, 17 triads); and (c) problematizing scaffolds (experimental group 2, 19 triads). The conditions were equally divided over the classes. By using randomly assigned triads to the conditions within a class, we blocked for effects of classes.

As coding all conversation turns from all triads requires enormous time, labor and resources, we randomly drew a smaller sample of 18 triads (one in each scaffolding condition from each class) for this study. The sample consists of 54 students ( 23 boys and 31 girls) assigned in six control triads, six triads in the structuring condition and six triads in the problematizing condition. The students of this sample were in Grade four (9), Grade five (27) or Grade six (18) across six classes in three elementary schools. These three schools were comparable, all in outer city suburban areas with a white middle class population. Within each class, equal numbers of triads were assigned to the different conditions, resulting in an equal allocation of triads in each scaffolding condition across schools. For a sample size of 54, an effect size of 0.4 and a significance level of $p=.05$, the statistical power is 0.86 . Hence, non-significant results at the individual level must be interpreted cautiously.

\section{Procedure}

Virtual learning environment and assignment

The e-learning environment in this study, Ontdeknet, supports students in their virtual collaboration with experts (Molenaar 2003). The experts shared information about their country with students that were edited by the editor of Ontdeknet. The teacher gave the assignment and monitored students' progress. Collaborative learning is implemented at two levels: students collaborating with each other face-to-face in small groups with a computer and with an expert in a virtual environment. The study consisted of eight lessons, each lasting one hour. In the first lesson, the students completed a pre-test, and then received instructions about the assignment and the virtual environment. In the last lesson, the students completed several post-tests. All students received the same instructions, and all triads spent the same time working on the assignment (six hours). During these six lessons, the triads worked on an assignment called "Would you like to live abroad?" The goal of the assignment was to explore a country of choice (New Zealand or Iceland), write a paper on their findings, and decide if they would like to live in that country. The triads worked on one computer and had access to an expert, namely an inhabitant of the country. They could consult the expert by asking questions and requesting information about different topics in the country. In a separate expert window in the computer environment, the expert provided the requested information, and questions were answered in a forum. Four sub-tasks preceded the task of writing a paper about the country: (a) introducing the group to the expert, (b) writing a goal statement, (c) selecting a country, and (d) specifying topics of interest on a mind map. All tasks were integrated into the working space of the triads, where they also wrote the paper. The performance of each triad was stored in the learning environment. All lessons were supervised by the same researcher. 
The scaffolding system and the conditions

Scaffolds are messages that support the learner in tasks that they cannot successfully perform without help (Wood et al. 1976). Both forms of metacognitive scaffolds were dynamically integrated into the computer environment. The triads of students in both experimental scaffolding conditions received computerized scaffolds supporting their metacognitive activities during the first two lessons at the same instance in the learning process (Molenaar and Roda 2008). These scaffolds were given when metacognitive activities are typically executed in the learning process. The timing was based on Zimmerman's model for self-regulated learning (Zimmerman 2002). The computerized scaffolding system determined the appropriate instance to send a scaffold based on the students' attention focus. Students in the scaffolding conditions received a minimum of 12 scaffolds in each condition. The triads in the structuring condition (experimental group one) received direct support for their metacognitive activities; for example, the computer avatar David showed the students an exemplary plan of a task "The expert would like to know what you want to learn. Please write all the topics about New Zealand that you would like to learn more about in this mind map" (see Fig. 2). In response, students can elaborate and reformulate the specifications to the planning activities of the group, see Fig. 2. The triads in the problematizing condition (experimental group two) received scaffolds designed to elicit students' metacognitive activities and explanations; for example, the computer avatar David asks, "How are you going to make a mind map?" The triads in the problematizing condition were obliged to answer the avatar's questions in an answer box on the screen, see Fig. 2. In response, students can construct a plan of how to make a mind map. Lastly, the control group triads saw the avatar David, but did not receive any metacognitive scaffolds (to control for a Hawthorne effect, in which the avatar's mere presence could influence the student activities, Franke and Kaul 1978).

\section{Measurements}

The learning activities

The conversations within each triad of students were audiotaped with voice-recorders. We coded the transcribed protocols of each lesson. The unit of analysis was the conversation turn of each speaker. Each conversation turn was coded with one main category code, see
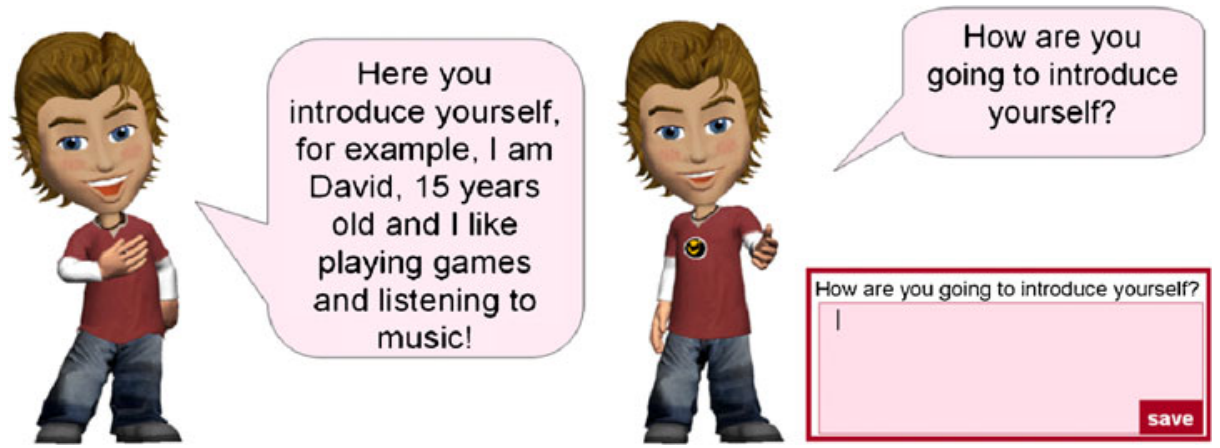

Fig. 2 Example of structuring (left) and problematizing (right) scaffolds 
Table 1 for an overview and one subcategory code, see Appendix A Tables 5, 6 and 7. All main categories were mutually exclusive and exhaustive categories, as were all subcategories within a main category.

Several categories (cognitive activities, metacognitive activities, off task activities, not codable activities and teacher activities) were derived from the coding scheme of VeldhuisDiermanse (2002). Additionally, two types of activities were added; relational activities specific for the group setting and procedural activities specific for our learning environment. In this analysis, we focus on cognitive, metacognitive, relational and offtask activities. The cognitive activity category contains turns regarding the content of the task and elaboration of this content (e.g., reading the material, asking a question about the domain, discussing the learning task, elaborating specific issues and summarizing previous contributions of group members, see Appendix A Table 5). Metacognitive activity includes turns that monitor or control cognitive activities, and includes Meijer et al. (2006) subcategories: orientation, planning, monitoring, evaluation and reflection (see Appendix A Table 6). Relational activity includes turns regarding the social interaction among students, such as engaging other group members, discussing the division of labor among the group members, and supporting other group members (see Appendix A Table 7). Off task refers to activities that are not related to either the learning task at hand or the task domain, and teacher activities are contributions made by the teacher.

To determine the inter-coder reliability, two raters independently coded two randomly selected protocols (2500 turns). There was an excellent agreement for the main categories (Fleiss 1981): Cohen's kappa $=0.92$. The kappa was highest for the metacognition category, $k=0.94$, and lowest for the non-codable category, $k=0.82$. The dataset consists of 51,339 activities at the conversation turn level across 108 hours of discourse.

Using these codes, we computed individual's and group mates' proportions of turns; for example, \% My cognitive activities = person's cognitive turns / total turns of group; \% Group mates' cognitive activities = group mates' cognition turns / total turns of group

We computed parallel pairs of variables for each main category. Furthermore, we analyzed all the responses of the triads to the scaffolds to select representative excerpts illustrating how the triads generally responded to the scaffolds.

Individual learning achievements

The individual learning achievements were assessed by measuring each student's domain and metacognitive knowledge on separate tests. Domain knowledge was measured by a

Table 1 Main categories of our coding scheme

\begin{tabular}{ll}
\hline Main category & Description \\
\hline Metacognitive activity & $\begin{array}{c}\text { Turns about monitoring and controlling the cognitive activities in the } \\
\text { learning process } \\
\text { Turns about the content of the task and the elaboration of this content }\end{array}$ \\
Regnitive activity & Turns regarding the social interaction between the students in the triad \\
Procedural activity & Turns regarding the procedures to use the learning environment \\
Teacher/researcher & Turns that are made by the teacher or the researcher. \\
Off task & Turns that are not relevant to the task. \\
Not codable & Turns that are too short or unclear to interpret \\
\hline
\end{tabular}


curriculum-based knowledge test with 40 questions (true/false/question mark) about the country the students had studied. Students received one point for each correct answer, and zero points for a question mark or an incorrect answer. The question mark option was included to reduce guessing, as we told the students that for each incorrect answer, one point would be subtracted from their test score. Cronbach's alpha was 0.93 for the New Zealand test and 0.88 for the Iceland test. This test was also used as a pre-test before students engaged in the learning assignment. The time between pre-test and post-test was eight weeks.

The metacognitive knowledge of the students was measured by asking them to imagine that they were going to do the same assignment again. They were asked to write down the steps that they would take to do this assignment. The answers were scored against a full procedural overview made by the researchers. The full procedural overview consisted of 18 steps; examples of steps were "plan the learning task", "activate prior knowledge" and "monitor the activity of the group." The maximum score was 18 points. Ten percent of the tests were scored by two independent researchers (kappa=0.83). We did not conduct a pre-test for metacognitive knowledge as the test was not suitable for that purpose.

\section{Analysis}

We used mixed methods to analyze the conversations of students in the different conditions. To understand how different scaffolds stimulate metacognitive activities among students, we used discourse analysis (Gee 2005). We selected representative excerpts of conversations in which students responded to different forms of metacognitive scaffolds, illustrating how they stimulate students' metacognitive activities, how students respond (active, constructive or interactive activities) and how they influence students' interactions.

To test these hypotheses, we must address analytical difficulties involving these outcome variables and these explanatory variables (see Table 2). There are two outcome variables, and they differ across groups and across individuals. To analyze the two outcome variables simultaneously (domain and metacognitive knowledge), we used a multivariate outcome model to account for contemporaneous correlation in the errors across equations (Goldstein 1995). To model differences across groups and across individuals simultaneously, we used a multilevel analysis (aka Hierarchical Linear Modeling, Bryk and Raudenbush 1992; Goldstein 1995) to account for heteroskedasticity.

Table 2 Addressing each analytical difficulty with a statistics strategy

\begin{tabular}{ll}
\hline Analytical difficulty & Statistics strategy \\
\hline Outcome variables & \\
- Multiple dependent variables & - Multivariate outcome models (Goldstein 1995) \\
- Differences across groups and & - Multilevel analysis (aka Hierarchical linear modeling, \\
across individuals & Bryk and Raudenbush 1992; Goldstein 1995) \\
$\begin{array}{l}\text { Explanatory variables } \\
\text { - Indirect, mediation effects } \\
\text { - False positives (Type I errors) }\end{array}$ & - Multilevel mediation tests (Krull and MacKinnon 2001) \\
\hline
\end{tabular}


The explanatory variables may show indirect, mediation effects or false positives. To test for multilevel, mediation effects, we used a multilevel, mediation test (Krull and MacKinnon 2001). Testing many hypotheses increases the likelihood that at least one of them incorrectly rejects a null hypothesis (false positive). To control for this false discovery rate, we used the two-stage linear step-up procedure, which outperformed 13 other methods in computer simulations (Benjamini et al. 2006).

The hypotheses were tested through a three-step process. First, we studied the influence of the control variables on test scores. Second, we conducted regression analyses to test the direct effect of different forms of metacognitive scaffolds on test scores and metacognitive activities. Finally, we tested the mediating influence of metacognitive activities on the relationship between metacognitive scaffolding and test scores with multi-level mediation tests (Krull and MacKinnon 2001).

We estimated a multivariate, multi-level regression of the following form:

$$
\text { Test }_{i g y}=\beta_{00 y}+\mathbf{f}_{0 g y}+\mathbf{e}_{i g y}
$$

$\beta_{00 y}$ are the grand mean intercepts of Test $\boldsymbol{~}_{i g y}$, a vector of $y$ outcome variables (domain knowledge test score and metacognitive knowledge test score) for student $i$ in group $g$. The group- and student-level residuals are $\mathbf{f}_{0 \mathrm{~g} y}$ and $\mathbf{e}_{i g y}$ respectively.

This study design seeks to control for students' abilities and gender influences. Specifically, each triad includes a student with high ability, one with medium ability, and one with a low ability. Furthermore, each triad included at least one girl. Regressions confirmed that neither domain knowledge test score nor metacognitive knowledge test score were associated with means or distributions of ability or gender.

To examine the link between scaffolding interventions and test scores, we entered a vector of $u$ scaffolding conditions: structuring and problematizing (Scaffold) with the control group as the baseline. Each set of predictors was tested for significance with a nested hypothesis test $\left(\chi^{2} \log\right.$ likelihood, Kennedy 2004).

$$
\text { Test }_{i g y}=\beta_{00 y}+\mathbf{e}_{i g y}+\mathbf{f}_{0 g y}+\beta_{s j y} \text { Scaffold }_{i g y}+\beta_{t g y} \operatorname{Turn}_{i g y}
$$

Then, we entered a vector of $x$ variables indicating specific conversation turn characteristics: total group turns, percentage of conversation turns in which a student engaged in each activity in their triad (total individual turns, cognitive activities, relational activities, procedural activities, and off-task activities, Turn), and percentages of the above activities of other group members.

Next, we tested whether the metacognitive scaffolding conditions were linked to the percentage of conversation turns in which a student engaged in metacognitive activities in a triad.

$$
\text { Metacognition }_{\text {igy }}=\beta_{00 \mathrm{y}}+\mathbf{e}_{\text {igy }}+\mathbf{f}_{\text {ogy }}+\beta_{\text {sgy }} \text { Scaffold }_{\text {igy }}+\beta_{\text {tjy }} \text { Turn }_{\text {igy }}
$$

Lastly, we added the percentage of conversation turns in which a student engaged in metacognitive activities in a triad (Metacognition) to Eq. 2. By doing this we can test our third hypothesis.

$$
\text { Test }_{\text {igy }}=\beta_{00 \mathrm{y}}+\mathbf{e}_{\text {igy }}+\mathbf{f}_{\text {ogy }}+\beta_{\text {sgy }} \text { Scaffold }_{\text {igy }}+\beta_{\text {tgy }} \text { Turn }_{\text {igy }}+\beta_{\text {1gy }} \text { Metacognition }_{\text {igy }}
$$

We used multi-level mediation tests across the above vectors (Krull and MacKinnon 2001). For significant mediators, the proportional change was $1-\left(b^{\prime} / b\right)$, where $b^{\prime}$ and $b$ were the regression coefficients of the explanatory variable, with and without the mediator in the model, respectively. 
We reported how a $10 \%$ increase in each continuous variable above its mean was linked to each outcome variable. As percent increase is not linearly related to standard deviation, scaling is not warranted.

An alpha level of .05 was used. Testing many hypotheses increases the likelihood that at least one of them incorrectly rejects a null hypothesis (false positive). To control for the false discovery rate, we used the two-stage linear step-up procedure, which outperformed 13 other methods in computer simulations (Benjamini et al. 2006).

\section{Results}

We start with our findings from the discourse analysis. By discussing two representative excerpts, we show how different forms of metacognitive scaffolds influence students' responses. Next, we illustrate how metacognitive activities influence peer interactions and foster domain and metacognitive knowledge. Lastly, we report the findings of the multivariate, multi-level analyses.

\section{Discourse analysis of representative excerpts}

First, we look at the student responses to different scaffolds. A structuring scaffold is typically followed by either the implementation of the scaffold example or a group discussion elaborating on the example. On the other hand, problematizing scaffolds elicit student activities, leading the group to elaborate, share knowledge, resolve a conflict or coconstruct new metacognitive activities. We illustrate this with two examples, the structuring scaffold excerpt in example one and the problematizing excerpt in example two.

\begin{tabular}{lll}
\hline $\begin{array}{l}\text { Speaker } \\
\text { Avatar }\end{array}$ & $\begin{array}{l}\text { Code } \\
\text { Structuring scaffold }\end{array}$ & $\begin{array}{l}\text { Conversation turn } \\
\text { A learning goal is what you want to learn. For instance, we would }\end{array}$ \\
$\begin{array}{ll}\text { Paul } \\
\text { Simon to learn more about New Zealand to decide if we would like }\end{array}$ \\
Loes & Metacognitive & Ok, so we will say \\
\hline
\end{tabular}

Example 1. An example of a response to a structuring scaffold (underlined texts is spoken by the avatar)

After the structuring scaffold, Paul accepted the example given ("Ok") and started to apply the example to their assignment with a planning activity ("we will say."). Simon and Loes finished his effort by applying the example of the avatar to their assignment "We are going to make a paper about Iceland." Unlike the structuring scaffold, the problematizing scaffold in example two stimulated a rich discussion about a learning goal's meaning, its purpose, and its role, rationale and implementation in this assignment.

$\begin{array}{ll}\text { Speaker } & \text { Code } \\ \text { Avatar } & \text { Problematizing scaffold } \\ \text { Mien } & \text { Metacognitive } \\ \text { Jan } & \text { Metacognitive }\end{array}$

Conversation turn

How are you going to write down a learning goal? What is a learning goal?

A learning goal is what you want to learn, for example I become a president. 


\begin{tabular}{lll} 
Joost & Metacognitive & For example, right? \\
Jan & Metacognitive & Yes for example there are many things you have to learn. \\
Joost & Metacognitive & Because we want to know things. \\
Mien & Metacognitive & Yes, but what do we want to learn now? \\
Jan & Metacognitive & We want to learn about a country to see if we want to live there. \\
Joost & Metacognitive & Right, and this we have to explain to the expert. \\
\hline
\end{tabular}

Example 2. An example of a response to a problematizing scaffold (underlined texts is spoken by the avatar)

The problematizing scaffold ignites a chain reaction of metacognitive activities. First, Mien asks for the meaning of a learning goal ("What is a learning goal?"). Jan answers by defining a learning goal as "what you want to learn" and by giving an example "become a president." After clarifying that "become president" was an example, Joost claims that the purpose of learning is "because we want to know things." In response, Mien asks for their immediate learning goal ("but what do we want to learn now"). Jan answers with their learning goal for this assignment ("We want to learn about a county,") and its rationale ("to see if we want to live there.") Joost concurs ("Right") and articulates its implementation, ("this we have to explain to the expert."). Through their exploration of the learning goal, the group members orient to the task and construct a better understanding of it. Each student's metacognitive activity triggers another group member's metacognitive activity. Furthermore, each metacognitive activity provides validating feedback to the previous one and provides grist from which to co-construct the next one, thereby valuing the importance of metacognitive activities and encouraging its subsequent use and development. Thus these two examples illustrate how the metacognitive activities elicited by problematizing scaffolds result in more student involvement and interaction, which seem qualitatively different than the activities stimulated by structuring scaffolds.

\section{Metacognitive activities as mediating mechanism}

Next, we illustrate how metacognitive activities mediate student learning during collaboration. First, we show an example that illustrates how metacognitive feedback is given during collaborative learning. Second, we show how metacognitive activities improve student's cognitive activities.

Metacognitive knowledge is developed through practices, examples and feedback. In example three, Joep contributes a plan ("let's write down hobbies") to write the introduction assignment. Eline and Noor immediately start implementing this plan ("My hobbies are tennis and ballet"). Eline's and Noor's contributions give feedback to Joep that his planning remark was useful. This feedback may positively influence Joep's metacognitive knowledge. In example two, there was a more elaborate interaction around metacognitive activities, in which group members actively construct metacognitive activities, but also built on one another's contributions. In these types of interactions, the elaboration, feedback and co-constructive contributions can help build students' metacognitive knowledge.

\begin{tabular}{lll}
\hline Student & Code & Conversation turns \\
Joep & Metacognitive & Let's write down hobbies \\
Eline & Cognitive & My hobbies are tennis and ballet \\
Noor & Cognitive & I play the guitar \\
\hline
\end{tabular}

Example 3. An example of metacognitive activity that is implemented through cognitive activity 
With respect to domain knowledge, cognitive activities build and elaborate on the topic studied. Metacognitive activities during interactions monitor and control these cognitive activities as shown in example 4.

\begin{tabular}{lll}
\hline Student & Code & Conversation turns \\
Ine & Cognitive & These are all products of New Zealand... not imported ... \\
Mark & Cognitive & Does have to import. \\
Ine & Cognitive & New Zealand that does import. \\
Sophie & Metacognitive & That is wrong, does not import. \\
Ine & Cognitive & All products of New Zealand, thus not imported. \\
Mark & Metacognitive & That is a good sentence. \\
Sophie & Metacognitive & Yes and now it is right, lets continue .... \\
\hline
\end{tabular}

Example 4. An example of cognitive and metacognitive activities

While writing their paper, Ine expressed a new idea ("not imported") and Mark wrote it down. When Mark misunderstands it ("does have to import"), Ine does not notice and repeats ("does import"). However, Sophie detects and corrects the error ("that is wrong, does not import"). Sophie's monitoring controls her group mates' cognitive activities. Next, Ine continues to clarify and correct the sentence ("not imported"). Mark evaluates and accepts it ("good sentence"), and Sophie confirms and plans to continue the formulation of the next sentence. Sophie's metacognitive activity improves her group's cognitive activities and receives validation from other group members, which highlights its importance and encourages its further use and development. This instance is likely to help the group members remember that New Zealand does not import all these products, thus affecting the group members' domain knowledge.

\section{Descriptive findings}

Starting with a low domain knowledge pre-test mean of 7.07 , the students scored much higher on its post-test $(M=20.72$; maximum=36). Scores on the subsequent metacognitive knowledge test were modest $(M=5.30$; maximum=12). During their group interactions, a student's activities included many cognitive activities $(9 \%$ of the triad's turns on average), metacognitive activities (7\%), relational activities (7\%) and fewer offtask activities (4\%). Other group members engaged in substantial relational activities (14\%). (The percentages do not sum to $100 \%$ due to codes for group mates' activities and for other activities, such as procedural activities. See summary statistics in Appendix B, Table 8.)

\section{Multilevel analyses}

The variance components multi-level model (intercept-only) for domain knowledge scores showed that $45 \%$ of the differences were between groups (suggesting substantial similarity among members of the same group), and 55\% were among students within each group (see Table 3). For metacognitive knowledge test scores, $65 \%$ of the differences were between groups (also showing substantial similarity among group mates) and 35\% were across students within each group. 
Table 3 Unstandardized regression coefficients (with Standard Errors) of multivariate, multilevel regression model results simultaneously predicting post-test and metacognitive knowledge test $(N=54)$

\begin{tabular}{|c|c|c|c|c|c|c|c|c|}
\hline \multirow[t]{2}{*}{ Explanatory variable } & \multicolumn{8}{|c|}{ Domain knowledge test } \\
\hline & Model $1^{\mathrm{a}}$ & & Model $2^{b}$ & & Model $3^{c}$ & & Model $4^{\mathrm{d}}$ & \\
\hline Structuring scaffolds & $2.65(1.92)$ & & & & $2.56(1.90)$ & & $1.92(1.67)$ & \\
\hline Problematizing scaffolds & $4.55(1.74)$ & $* *$ & & & $4.26(1.62)$ & $*$ & $2.75(1.66)$ & \\
\hline$\%$ My Cognitive activities & & & $63.53(26.06)$ & * & $59.09(23.03)$ & $*$ & $57.85(23.02)$ & $*$ \\
\hline $\begin{array}{l}\text { \% Group mates' relational } \\
\text { activities }\end{array}$ & & & $66.76(28.04)$ & $*$ & $60.09(27.84)$ & $*$ & $58.64(23.23)$ & $*$ \\
\hline $\begin{array}{l}\% \text { My Metacognitive } \\
\text { activities }\end{array}$ & & & & & & & $90.67(35.52)$ & $*$ \\
\hline Variance at each level & \multicolumn{8}{|c|}{ Explained variance at each level } \\
\hline Group level (45\%) & 0.12 & & 0.08 & & 0.28 & & 0.29 & \\
\hline Student level $(55 \%)$ & 0.14 & & 0.15 & & 0.15 & & 0.21 & \\
\hline Total variance explained & 0.13 & & 0.12 & & 0.21 & & 0.25 & \\
\hline \multirow[t]{2}{*}{ Explanatory variable } & \multicolumn{8}{|c|}{ Metacognitive Knowledge Test } \\
\hline & Model $1^{\mathrm{a}}$ & & Model $2^{b}$ & & Model $3^{c}$ & & Model $4^{\mathrm{d}}$ & \\
\hline Structuring scaffolds & $1.98(0.76)$ & $* *$ & & & $1.89(0.75)$ & $*$ & $0.27(0.80)$ & \\
\hline Problematizing scaffolds & $2.19(0.75)$ & $* *$ & & & $2.03(0.72)$ & $*$ & $0.46(0.74)$ & \\
\hline$\%$ My Cognitive activities & & & $23.17(9.63)$ & $*$ & $22.94(9.71)$ & $*$ & $27.73(9.02)$ & $* *$ \\
\hline$\%$ My Off-task activities & & & $-43.05(13.01)$ & $* *$ & $-37.03(16.00)$ & $*$ & $-30.41(12.35)$ & $*$ \\
\hline $\begin{array}{l}\% \text { My Metacognitive } \\
\text { activities }\end{array}$ & & & & & & & $30.14(14.38)$ & $*$ \\
\hline Variance at each level & \multicolumn{8}{|c|}{ Explained variance at each level } \\
\hline Group level $(65 \%)$ & 0.37 & & 0.13 & & 0.37 & & 0.37 & \\
\hline Student level $(35 \%)$ & 0.00 & & 0.21 & & 0.21 & & 0.42 & \\
\hline Total variance explained & 0.24 & & 0.33 & & 0.36 & & 0.39 & \\
\hline
\end{tabular}

${ }^{\text {a }}$ Model 1: Explanatory variables only include metacognitive scaffolding conditions

${ }^{\mathrm{b}}$ Model 2: Explanatory variables only include significant turns characteristics other than \% my metacognitive activities

${ }^{\mathrm{c}}$ Model 3: Explanatory variables include metacognitive scaffolding conditions and significant turn characteristics other than \% my metacognitive activities

${ }^{\mathrm{d}}$ Model 4: Explanatory variables include all scaffolding conditions and significant turn characteristics

Relation between metacognitive scaffolds and learning

Hypothesis 1 concerned the direct effect of scaffolding and different scaffolds on domain and metacognitive knowledge. Findings indicate that students in the structuring and problematizing condition outscored students in the control condition on the domain knowledge post-test by 2.65 (not significant) and 4.55 (significant) points respectively on average (see Table 3, Domain knowledge, Model one). Furthermore, students whose proportion of cognitive activities exceeded its mean by $10 \%$ averaged 6.35 points higher on the post-test (see Table 3, Domain knowledge, Model two). When other group members' proportion of relational activities exceeded its mean by $10 \%$, a student averaged 6.67 points higher (see Table 3, Domain 
knowledge, Model two). Controlling for other learning activities (cognitive and relational activities), regression coefficients of the different scaffolds on domain knowledge are only slightly smaller (see Table 3, Domain knowledge, Model three). Students in the problematizing condition still outperformed students in the other conditions.

Students in the structuring and problematizing conditions outscored students in the control condition by 1.98 or 2.19 points respectively on the metacognitive knowledge test on average (see Table 7 in Appendix B, Metacognitive knowledge, model one). Furthermore, students whose proportion of cognition turns exceeded its mean by $10 \%$ averaged 2.32 points higher, respectively, on the metacognitive knowledge test (see Table 3, Metacognitive knowledge, model two). In contrast, students whose proportion of off-task behaviors exceeded its mean by $10 \%$ averaged 4.31 points lower on the metacognitive knowledge test (see Table 3, Metacognitive knowledge, model two). Controlling for other learning activities (cognitive activities and relational activities), the findings show that the effect of problematizing scaffolds on metacognitive knowledge, although a little bit smaller, is still stronger compared to structuring scaffolds (see Table 3, Metacognitive knowledge, Model three). Controlling for other learning activities, students in the problematizing scaffolds condition still outperformed students in the other conditions.

Hypothesis 2 concerned the effect of scaffolding and different scaffolds on metacognitive activities. The results in Table 4 show that the students receiving metacognitive scaffolding displayed proportionately more metacognitive activities than other students. Students receiving problematizing scaffolds showed slightly more metacognitive activities than students receiving structuring scaffolds, but this difference was not significant.

Hypothesis 3 concerned the extent to which metacognitive activities mediate the relationship between different scaffolds and students' domain knowledge and metacognitive knowledge. The findings show that students whose proportion of metacognition exceeded their mean by $10 \%$ averaged 9.06 points higher on the post-test (see Table 3, Domain knowledge, Model four). Controlling for individual proportion of metacognitive actions reduced the problematizing scaffold condition regression coefficient by $35 \%$ (multi-level mediation test $z=$ 2.02; $\mathrm{p}<.05 ; r=.50$; Table 3, Domain knowledge, Models three and four). Together, these explanatory variables accounted for $25 \%$ of the domain knowledge post-test score variance.

With regard to the mediating effect of metacognitive activities on metacognitive knowledge, the findings show that students whose proportion of metacognition exceeded their mean by $10 \%$ averaged 3.01 points higher on the post-test (see Table 3, Metacognitive knowledge, Model four). Controlling for individual proportion of metacognitive actions reduced the structuring scaffold and problematizing scaffold conditions' regression coefficients by $86 \%$ and $77 \%$ respectively (multilevel mediation tests: $z=2.02 ; p<.05$;

Table 4 Unstandardized regression coefficients (with Standard Errors) of multivariate, multilevel regression model results predicting the $\%$ of metacognition $(N=54)$

\begin{tabular}{lll}
\hline Explanatory variable & $\%$ Metacognition & $* *$ \\
\hline Structuring scaffolds & $0.017(0.006)$ & $* *$ \\
Problematizing scaffolds & $0.020(0.006)$ & \\
Variance at each level & Explained variance at each level \\
Group level (33\%) & .558 \\
Student level (67\%) & .000 \\
Total variance explained & .186 \\
\hline
\end{tabular}


$r=.39$; and $z=2.01 ; p<.05 ; r=.50)$. Together, these explanatory variables accounted for $39 \%$ of the metacognitive knowledge test score variance.

\section{Discussion}

In this study, we examined to what extent metacognitive activities mediated the effect of different scaffolds on students' domain knowledge and metacognitive knowledge. Three hypotheses were assessed to answer this question. The first hypothesis addressed whether different forms of metacognitive scaffolding affected students' metacognitive knowledge and domain knowledge. In the structuring condition, the avatar showed contextually suitable examples of metacognitive activities, whereas in the problematizing condition it posed questions to elicit metacognitive activities. Both metacognitive scaffolds (structuring and problematizing) were associated with higher scores on the metacognitive knowledge test. Only problematizing scaffolds were linked to greater domain knowledge; structuring scaffolds did not significantly affect domain knowledge. With regard to the second hypothesis, the findings show that scaffolding stimulated metacognitive activities (the two scaffolds did not differ significantly). Regarding the third hypothesis, students receiving either metacognitive scaffold engaged in more metacognitive activities, which were linked to their higher metacognitive knowledge test scores. Meanwhile, only problematizing scaffolds were linked to greater domain knowledge, and individual metacognitive activities also mediated this relationship.

These findings suggest that both forms of scaffolding affect students' metacognitive knowledge, mainly through the metacognitive activities that they stimulate. Contrary to our expectations, we did not find a significant difference in the number of metacognitive activities in each scaffolding condition. However, only problematizing scaffolds were linked to greater domain knowledge, suggesting that the metacognitive activities elicited by problematizing scaffolds differed from those elicited by structuring scaffolds. The discourse analysis suggests that structuring scaffolds encouraged students to discuss the application of the example while problematizing scaffolds stimulated students to construct metacognitive activities in interaction with their group members. Hence, structuring scaffolds might foster active metacognitive activities from the students, whereas problematizing scaffolds might trigger more constructive activities embedded in intensive interaction. Constructive activities are likely more effective than active activities at aiding knowledge acquisition (Chi 2009). Thus, this qualitative difference in the student interactions might help explain why problematizing scaffolds were associated with greater domain knowledge, while structuring scaffolds were not. This is an important finding because it suggests that the effect of metacognitive scaffolds on learning operates through both a greater number of metacognitive activities within the group and the student's own involvement in the metacognitive activities.

Finally, we controlled for other learning activities that can affect learning during collaboration (Janssen et al 2010; McGrath 1991). The analysis showed that both forms of metacognitive scaffolds were associated with greater metacognitive activities without significantly influencing other activities. Yet, other learning activities did influence students' metacognitive knowledge and domain knowledge. Students performing proportionately more cognitive or metacognitive activities scored higher on both the domain knowledge test and the metacognitive knowledge test, consistent with earlier findings (Janssen et al 2010). However, other group members' cognitive and metacognitive activities did not significantly contribute to a student's domain or metacognitive knowledge in this study, in contrast to earlier studies claiming that students' elaborations on one another's 
contributions fosters learning (Chi 2009; Mercer 1996; Piaget 1932; Webb 2009; Weinberger \& Fischer, 2006; van Boxtel 2004). This issue needs more attention in future research especially since we know so little about how metacognitive activities embedded in interaction influence students' learning (Dillenbourg et al 2009; Iiskala et al. 2010).

We did find some evidence that group mates influence a student's learning. When a student's group mates performed proportionately more relational activities, the student scored higher on the domain knowledge test. Relational activities were previously found to foster a positive group climate (Kreijns et al. 2003; Massey et al 2003; McGrath 1991; Jehn and Shah 1997; Wilson et al. 2006), but were not yet explicitly connected to learning. This study suggests that group mates' relational activities (but not one's own) foster a student's learning of domain knowledge. An example of how the relational activities can influence the domain knowledge is given in Appendix C. Finally, students who were often off-task scored lower on the metacognitive knowledge test, but not on the domain knowledge test, unlike previous studies linking off task activity with less domain knowledge (e.g., Chiu 2004). Overall, these results highlight the effects of different activities on learning and the importance of distinguishing between the student's activities and those of group mates.

In summary, the problematizing scaffold is more strongly linked to student learning than the structuring scaffold is, perhaps due to the qualitative differences in their respective students' metacognitive activities. However, we have not systematically investigated the effects of different scaffolds on student involvement in the group interactions throughout the whole learning assignment. Interaction patterns are often established early in the learning assignment and remain rather stable through the collaboration (Kapur et al. 2008). This could entail that groups supported with problematizing scaffolds continue to show more intensive interaction through the learning assignment. Future research can examine how scaffolding influences the interaction among the group members during earlier and later time periods of their collaboration. Finally as discussed above, metacognitive activities have received relatively little attention in collaborative learning research as an explanatory factor for learning (Dillenbourg et al. 2009). We showed that they influence student domain and metacognitive knowledge in collaborative settings, but further research can examine how they are embedded in interaction and how that influences their monitoring and control of cognitive activities.

\section{Conclusions}

In this study, we examined if metacognitive activities mediate the learning effects of metacognitive scaffolding. Our analysis of the discourses and achievements of 54 elementary school students showed that students receiving either form of metacognitive scaffolds (structuring or problematizing) engaged in more metacognitive activities and showed more metacognitive knowledge than students who did not receive any scaffolding. However, only students receiving problematizing scaffolds showed greater domain knowledge, which was also mediated by their own metacognitive knowledge. The discourse analysis suggests that qualitative differences in students' metacognitive activities can account for the differences between problematizing and structuring scaffolds. These results suggest the superiority of problematizing scaffolds over structuring scaffolds for some tasks.

This study has several limitations regarding sample size, the interaction context of the metacognitive activities, and time/sequence. As this study only has 54 students, non-significant results at the student level must be interpreted cautiously (even though there are 51,339 conversation turns). Meanwhile, we did not examine the micro-time context of recent conversation turns in which metacognitive activities are embedded. One approach to modeling 
the micro-time context is to examine the characteristics of sequences of recent conversation turns. The impact of a student activity (e.g., metacognition) might differ across micro-time contexts. Likewise, the impact of a student activity (e.g., planning) at the beginning of the session (earlier time period) might differ from the same activity at the end of a session (later time period, Reimann 2009). Lastly, different sequences of the same set of activities (M,C,M,C,M, C vs. M,M,M,C,C,C) may have different effects on student learning (Chiu 2008).

On a practical level, the results suggest that problematizing scaffolds and some activities in collaborative settings can aid learning. Specifically, designing problematizing metacognitive scaffolds into virtual learning environments for some tasks can enhance individual group members' metacognitive activities to aid acquisition of domain knowledge and metacognitive knowledge more than learning environments with structuring scaffolds or with no scaffolds. Furthermore, instructional designs might enhance individual group member's domain knowledge by engaging all group members in cognitive and metacognitive activities and encouraging group members to engage in relational activities. Additionally, instructional designs might enhance individual group members' metacognitive knowledge by engaging all group members in cognitive and metacognitive activities and by reducing their off task behavior.

Acknowledgements This research was supported by grants from the National Scientific Organization of the Netherlands (NWO) 411-04-102 and from the European Commission under the FP6 Framework project Atgentive IST 4-027529-STP. We acknowledge the contribution of all Atgentive project partners to the development of the AtgentSchool scaffolding system, especially the work of Claudia Roda. We appreciate Yik Ting Choi's research assistance.

Open Access This article is distributed under the terms of the Creative Commons Attribution Noncommercial License which permits any noncommercial use, distribution, and reproduction in any medium, provided the original author(s) and source are credited.

\section{Appendix A}

Appendix coding schema

Table 5 Subcategories of cognitive activities

\begin{tabular}{|c|c|c|}
\hline Cognitive activities & Description & Examples \\
\hline Reading out & $\begin{array}{l}\text { Reading out the information from the } \\
\text { instruction, the learning environment } \\
\text { or statements of the avatar. }\end{array}$ & $\begin{array}{l}\text { You are going to write a paper. } \\
\text { My name is Jan I live in Iceland...... }\end{array}$ \\
\hline Processing & $\begin{array}{l}\text { Cognitive processing of the task through: } \\
\text { Selection of pictures } \\
\text { Writing of text } \\
\text { Naming mind map words }\end{array}$ & $\begin{array}{l}\text { I find this picture goes with the texts } \\
\text { In New Zealand there are many } \\
\text { different animals..... }\end{array}$ \\
\hline Questioning & $\begin{array}{l}\text { Asking a question that is related to the } \\
\text { content of the task }\end{array}$ & Do Maoris live in New Zealand? \\
\hline Elaboration & $\begin{array}{l}\text { Elaboration of task content: relating to } \\
\text { other concepts, giving examples or } \\
\text { connecting to own experiences. }\end{array}$ & $\begin{array}{l}\text { If there are mountains, it is probably } \\
\text { quite high } \\
\text { No, you also find tobacco in } \\
\text { cigarettes }\end{array}$ \\
\hline Summarizing & Summarizing what has been said before & $\begin{array}{l}\text { We have windmills, tulips, traditional } \\
\text { clothing and cheese }\end{array}$ \\
\hline
\end{tabular}


Table 6 Subcategories of metacognitive activities

\begin{tabular}{|c|c|c|}
\hline $\begin{array}{l}\text { Metacognitive } \\
\text { activities }\end{array}$ & Description & Examples \\
\hline Orientation & $\begin{array}{l}\text { Orientation on prior knowledge, task demands } \\
\text { and feelings about the task }\end{array}$ & $\begin{array}{l}\text { What do we need to do? } \\
\text { Do you know what a learning goal is? }\end{array}$ \\
\hline Planning & $\begin{array}{l}\text { Planning of the learning process, for instance, } \\
\text { sequencing of activities or choice of strategies }\end{array}$ & Now we are going to ask questions. \\
\hline Monitoring & $\begin{array}{l}\text { Monitoring of the learning process: checking } \\
\text { progress and comprehension of the task. }\end{array}$ & $\begin{array}{l}\text { I do not understand } \\
\text { You are doing it wrong } \\
\text { Wait, please just leave it like that }\end{array}$ \\
\hline Evaluation & $\begin{array}{l}\text { Evaluation of the learning process; checking } \\
\text { of the content of the learning activities. }\end{array}$ & $\begin{array}{l}\text { We posted a good question } \\
\text { These are the most important issues }\end{array}$ \\
\hline Reflection & $\begin{array}{l}\text { Reflection on the learning process and strategies } \\
\text { through elaboration on the learning process. }\end{array}$ & $\begin{array}{l}\text { Let me think, this is more difficult than I } \\
\text { thought. } \\
\text { Why do we have the most difficult task? }\end{array}$ \\
\hline
\end{tabular}

Table 7 Subcategories of relational activities

\begin{tabular}{|c|c|c|}
\hline Relational activities & Description & Examples \\
\hline Engaging & Asking group members to engage in the task & $\begin{array}{l}\text { Daniek please continue } \\
\text { Jocye that is not funny. }\end{array}$ \\
\hline Task division & Division of tasks between the group members & $\begin{array}{l}\text { She is thinking, I am asking } \\
\text { questions and you write } \\
\text { Pascall is typing }\end{array}$ \\
\hline Support & Repetition or support of a previous speaker & $\begin{array}{l}\text { We have to write a paper } \\
\text { Yes, we have to write it }\end{array}$ \\
\hline Reject & Rejection of previous speaker & $\begin{array}{l}\text { No } \\
\text { Do not do that! }\end{array}$ \\
\hline
\end{tabular}




\section{Appendix B}

Ancillary tables and results

Table 8 Summary statistics $(N=54)$

\begin{tabular}{llllll}
\hline Variable & Mean & S. D. & Min & Median & Max \\
\hline Domain Knowledge Post-test & 20.72 & 5.83 & 8 & 20 & 36 \\
Domain Knowledge Pre-test & 7.07 & 3.37 & 0 & 7.5 & 16 \\
Metacognitive knowledge Post- test & 5.30 & 2.41 & 1 & 5 & 12 \\
Structuring scaffolds & 0.33 & 0.48 & 0 & 0 & 1 \\
Problematizing scaffolds & 0.33 & 0.48 & 0 & 0 & 1 \\
\% My Cognitive activities & 0.09 & 0.03 & 0.01 & 0.09 & 0.18 \\
\% My Metacognitive activities & 0.07 & 0.02 & 0.01 & 0.07 & 0.12 \\
\% My Procedural activities & 0.04 & 0.02 & 0.01 & 0.04 & 0.11 \\
\% My relation activities & 0.07 & 0.02 & 0.01 & 0.07 & 0.11 \\
\% My Off-task activities & 0.04 & 0.03 & 0.01 & 0.03 & 0.13 \\
\% Group mates' Cognitive activities & 0.18 & 0.04 & 0.09 & 0.18 & 0.28 \\
\%Group mates' Metacognitive activities & 0.13 & 0.03 & 0.07 & 0.14 & 0.19 \\
\% Group mates' Procedural activities & 0.08 & 0.02 & 0.05 & 0.09 & 0.14 \\
\% Group mates' Relational activities & 0.14 & 0.03 & 0.05 & 0.15 & 0.19 \\
\% Group mates' Off-task activities & 0.07 & 0.04 & 0.01 & 0.06 & 0.22 \\
\hline
\end{tabular}

Table 9 Correlations, variances, and co-variances are along the lower left triangle, diagonal, and upper right triangle of the matrix $(N=54)$

\begin{tabular}{llllllllll}
\hline & Variable & 1 & 2 & 3 & 4 & 5 & 6 & 7 & 8 \\
\hline 1 & Domain Knowledge Post-Test & 32.02 & 5.98 & 0.23 & 0.70 & 0.06 & 0.06 & -0.04 & 0.02 \\
2 & Metacognitive knowledge Post- Test & 0.47 & 5.09 & 0.17 & 0.24 & 0.03 & 0.03 & -0.03 & 0.01 \\
3 & Structuring scaffolds & 0.09 & 0.17 & 0.22 & -0.11 & 0.00 & 0.00 & -0.01 & 0.00 \\
4 & Problematizing scaffolds & 0.26 & 0.23 & -0.49 & 0.22 & 0.00 & 0.00 & 0.00 & 0.00 \\
5 & \% My Cognitive activities & 0.34 & 0.46 & -0.04 & 0.04 & 0.00 & 0.00 & 0.00 & 0.00 \\
6 & \% My Metacognitive activities & 0.49 & 0.56 & 0.39 & 0.50 & 0.35 & 0.00 & 0.00 & 0.00 \\
7 & \% My Off-task activities & -0.28 & -0.44 & -0.42 & -0.19 & 0.08 & -0.33 & 0.00 & 0.00 \\
8 & \% Group mates' relational activities & 0.12 & 0.13 & 0.10 & -0.15 & -0.19 & -0.12 & -0.35 & 0.00 \\
\hline
\end{tabular}




\section{Appendix C}

Example of how relational activities influence domain knowledge

Relational activities

Other group members' relational activities can engage a student and thereby aid the student's learning, as shown in example 5. While Els and Joris are discussing the task, they notice that Lies is not engaged.

\begin{tabular}{lll}
\hline Student & Code & Conversation turn \\
Els & Relational activities & Lies, what are you doing? \\
Joris & Relational activities & Lies can you write this down? \\
Lies & Relational activities & Yes, I am sorry, where are we? \\
\hline
\end{tabular}

Example 5. An example of social regulation engaging group members

Els calls Lies by his name to get his attention ("Lies") and asks him, "what are you doing?" (social regulation-engaging). Joris further specifies a task for Lies to do ("can you write this down," social regulation-division of labor). In response, Lies agrees ("yes"), apologizes ("sorry") and starts attending to their task ("where are we?"), thereby aiding his subsequent domain knowledge acquisition. This example shows how other group members' relational activities can engage a student to work on the task and thereby aid the student's learning. Having illustrated the two types of metacognitive scaffolds and the students' activities, we statistically test these relationships.

\section{References}

Azevedo, R., \& Cromley, J. G. (2004). Does training on self-regulated learning facilitate students' learning with hypermedia? Journal of Educational Psychology, 96(3), 523-535.

Azevedo, R., \& Hadwin, A. F. (2005). Scaffolding self-regulated learning and metacognition-implications for the design of computer-based scaffolds. Instructional Science, 33(5-6), 367-379.

Azevedo, R., Moos, D. C., Greene, J. A., Winters, F. I., \& Cromley, J. G. (2008). Why is externallyfacilitated regulated learning more effective than self-regulated learning with hypermedia? Educational Technology Research and Development, 56(1), 45-72.

Benjamini, Y., Krieger, A. M., \& Yekutieli, D. (2006). Adaptive linear step-up procedures that control the false discovery rate. Biometrika, 93, 491-507.

Bryk, A. S., \& Raudenbush, S. W. (1992). Hierarchical linear models. London: Sage.

Chi, M. (2009). Active-constructive-interactive: A conceptual framework for differentiating learning activities. Topics in Cognitive Science, 1(1), 73-105.

Chi, M., Siler, S., Jeong, H., Yamuachi, T., \& Hausmann, R. (2001). Learning from human tutoring. Cognitive Science, 25, 471-533.

Chinn, C. A., O'Donnell, A. M., \& Jinks, T. S. (2000). The structure of discourse in collaborative learning. The Journal of Experimental Education, 69(1), 77-97.

Chiu, M. (2004). Adapting teacher interventions to student needs during cooperative learning: How to improve student problem solving and time on-task. American Educational Research Journal, 41, 365-399.

Chiu, M. M. (2008). Flowing toward correct contributions during groups' mathematics problem solving: A statistical discourse analysis. The Journal of the Learning Sciences, 17(3), 415-463.

Chiu, M. M., \& Khoo, L. (2003). Rudeness and status effects during group problem solving. Journal of Educational Psychology, 95, 506-523.

Coleman, E. B., Brown, A. L., \& Rivkin, I. D. (1997). The effect of instructional explanations on learning from scientific texts. The Journal of the Learning Sciences, 6, 347-365. 
Davis, E. A., \& Linn, M. (2000). Scaffolding Students' knowlegde integration; Prompts for reflection in KIE. International Journal of Science Education, 22(8), 819-837.

Dillenbourg, P., Järvelä, S., \& Fischer, F. (2009). The evolution of research on computer-supported collaborative learning: From design to orchestration. In N. Balacheff, S. Ludvigsen, T. de Jong, T., A. Lazonder \& S. Barnes(Eds.), Technology-Enhanced Learning. Principles and products, p. 3-19, Springer.

Doise, W. (1990). The development of individual competencies through social interaction. In H. C. Foot, M. J. Morgan, \& R. H. Shute (Eds.), Children helping children (pp. 43-64). New York, NY: John Wiley and Sons.

Doise, W., \& Mugny, G. (1984). The social development of the intellect. Oxford: Pergamon press.

Duffy, T. M., \& Jonassen, D. H. (1992). Constructivism and the technology of instruction: A conversation. Hillsdale: Lawrence Erlbaum Association.

Flavell, J. H. (1979). Metacognition and cognitive monitoring: A new area of cognitive-developmental inquiry. American Psychologist, 34(10), 906-911.

Fleiss, J. (1981). Statistical itletlzods for rates and proportions. New York: John Wiley and Sons.

Franke, R. H., \& Kaul, J. D. (1978). The Hawthorne experiments: First statistical interpretation. American Sociological Review, 43, 623-643.

Gee, J. P. (2005). An Introduction to discourse analysis: Theory and method. London: Routledge.

Goldstein, H. (1995). Multilevel statistical models. Sydney: Edward Arnold.

Goos, M., Galbraith, P., \& Renshaw, P. (2002). Socially mediated metacognition: Creating collaborative zones of proximal development in small group problem solving. Educational Studies in Mathematics, 49, 193-223.

Hatano, G. (1993). Time to merge Vygotskian and constructivist conceptions of knowledge acquisition. In E. A. Forman, N. Minick, \& C. A. Stone (Eds.), Contexts for learning: Sociocultural dynamics in children's development (pp. 153-166). New York, NY: Oxford University Press.

Hmelo-Silver, C. E., \& Azevedo, R. (2006). Understanding complex systems: Some core challenges. The Journal of the Learning Sciences, 15(1), 53-61.

Hausmann, R., Chi, M. T. H., \& Roy, M. (2004). Learning from collaborative problem solving: An analysis of three hypothesized mechanisms. In K. D. Forbus, D. Gentner, \& T. Regier (Eds.), Proceedings of the 26th Annual Conference of the Cognitive Science Society (pp. 547-552). Mahwah, NJ: Erlbaum.

Howe, C., Tolmie, A., Thurston, A., Topping, K., Christie, D., Livingston, K., et al. (2007). Groupwork in elementary science: Towards organisational principles for supporting pupil learning. Learning and Instruction, 17, 549-563.

Iiskala, T., Vauras, M., \& Lehtinen, E. (2004). Socially-shared metacognition in peer learning? Hellenic Journal of Psychology, 1(2), 147-178.

Iiskala, T., Vauras, M., Lehtinen, E., \& Salonen, P. (2010). Socially shared metacognition within primary school pupil Dyads' collaborative processes. Learning and Instruction, 21, 379-393.

Janssen, J., Erkens, G., Kirschner, P., \& Kanselaar, G. (2010). Task-related and social regulation during online collaborative learning. Metacognition and Learning, 1-19.

Jehn, K. A., \& Shah, P. P. (1997). Interpersonal relationships and task performance: An examination of mediation processes in friendship and acquaintance groups. Journal of Personality and Social Psychology, 72, 775-790.

Kapur, M., Voiklis, J., \& Kinzer, C. (2008). Sensitivities to early exchange in synchronous computersupported collaborative learning. Computers in Education, 51, 54-66.

Kennedy, P. (2004). A guide to econometrics. Cambridge: Blackwell.

King, A. (1998). Transactive peer tutoring: Distributing cognition and metacognition. Educational Psychology Review, 10(1), 57-74.

King, A. (2002). Promoting thinking through peer learning. Theory into Practice, 41(1), 33-39.

Kreijns, K., Kirschner, P. A., \& Jochems, W. (2003). Identifying the pitfalls for social interaction in computer-supported collaborative learning environments: A review of the research. Computers in Human Behavior, 19, 335-353.

Krull, J. L., \& MacKinnon, D. P. (2001). Multilevel modeling of individual and group level mediated effects. Multivariate Behavioral Research, 36, 249-277.

Land, S. M., \& Green, B. A. (2000). Project-based learning with the World Wide Web: A qualitative study of resource integration. Educational Technology Research and Development, 48(1), 45-67.

Lin, X., \& Sullivan, F. R. (2008). Computer context for supporting metacognitive learning. In J. Voogt \& G. Knezek (Eds.), International handbook of information technology in primary and secondary education (Vol. 1, pp. 281-298). New York: Springer.

Manlove, S., Lazonder, A. W., \& De Jong, T. (2006). Regulative support for collaborative scientific inquiry learning. Journal of Computer Assisted Learning, 22(2), 87-98. 
Massey, A. P., Montoya-Weiss, M. M., \& Hung, Y. (2003). Because time matters temporal coordination in global virtual teams. Journal of Management Information Systems, 19, 129-155.

Mayer, R. E., \& Wittrock, M. C. (1996). Problem-solving transfer. In R. Calfee \& R. Berliner (Eds.), Handbook of educational psychology (pp. 47-62). New York: Macmillan.

McGrath, J. E. (1991). Time, interaction, and performance (TIP). Small Group Research, 22, 147-174.

Meijer, J., Veenman, M. V., \& van Hout-Wolters, B. H. (2006). Metacognitive activities in text-studying and problem-solving: Development of a taxonomy. Educational Research and Evaluation, 12(3), 209-237.

Mercer, N. (1996). The quality of talk in children's collaborative activity in the classroom. Learning and Instruction, 6, 359-377.

Molenaar, I. (2003). Knowledge exchange from citizens to learners through online collaboration: Edmedia conference.

Molenaar, I., \& Roda, C. (2008). Attention management for dynamic and adaptive scaffolding. Pragmatics \& Cognition, 16(2), 224-271.

Molenaar, I., van Boxtel, C. A. M., \& Sleegers, P. J. C. (2010). The effects scaffolding metacognitive activities in small groups. Computers in Human Behavior, 26(6), 1727-1738.

Molenaar, I., van Boxtel, C. A. M., \& Sleegers, P. J. C. (in press). Metacognitive scaffolding in an innovative learning arrangement. Instructional Science.

Pea, R. D. (2004). The social and technological dimensions of scaffolding and related theoretical concepts for learning, education and human activity. The Journal of the Learning Sciences, 13(3), 423-451.

Piaget, J. (1932). The language and thought of the child (2nd ed.). London: Routledge and Kegan Paul.

Reimann, P. (2009). Time is precious: Variable- and event-centred approaches to process analysis in CSCL research. International Journal of Computer-supported Collaborative Learning, 3, 239-257.

Reiser, B. J. (2004). Scaffolding complex learning: The mechanisms of structuring and problematizing student work. The Journal of the Learning Sciences, 13(3), 273-304.

Salomon, G. (1993). Distributed cognitions; psychological and educational considerations. Cambridge: Cambridge University Press.

Sharma, P., \& Hannafin, M. J. (2007). Scaffolding in technology-enhanced learning environments. Interactive Learning Environments, 15(1), 27-46.

Schwartz, D. L., \& Bransford, J. D. (1998). A time for telling. Cognition and Instruction, 16, 475-522.

Van Boxtel, C. (2004). Studying peer interaction from three perspectives: The example of collaborative concept learning. In J. L. van der Linden \& P. Renshaw (Eds.), Dialogic learning: Shifting perspectives to learning, instruction and teaching (pp. 125-144). Dordrecht: Kluwer Academic Publishers.

Van Drie, J., \& Van Boxtel, C. (2004). Historical reasoning: A comparison of how experts and novices contextualise historical sources. International Journal of Historical Learning, Teaching and Research, 4 (2), 84-91.

Veenman, M. V. J. (2005). The assessment of metacognitive skills: What can be learned from multimethod designs? In C. Artelt \& B. Moschner (Eds.), Lernstrategien und Metakognition: Implikationen für Forschung und Praxis (pp. 75-97). Berlin: Waxmann.

Veenman, M. V. J. (2011). Learning to self-monitor and self-regulate. In R. Mayer \& P. Alexander (Eds.), Handbook of research on learning and instruction. New York: Routledge.

Veenman, M. V. J., Kok, R., \& Blote, A. W. (2005). The relation between intellectual and metacognitive skills in early adolescence. Instructional Science, 33(3), 193-211.

Veldhuis-Diermanse, A. E. (2002). CSCL-Learning? Participation, learning activities and knowledge construction in computer-supported collaborative learning in higher education. University of Wageningen.

Volet, S., Vauras, M., \& Salonen, P. (2009). Self- and social regulation in learning contexts: An integrative perspective. Educational Psychologist, 44(4), 215-226.

Webb, M. (2009). The teacher's role in promoting collaborative dialogue in the classroom. British Journal of Educational Psychology, 79, 1-28.

Webb, N. M., Nemer, K. M., \& Zuniga, S. (2002). Short circuits or superconductors? Effects of group composition on high-achieving students' science performance. American Educational Research Journal, 39, 943-989.

Weinberger, A., \& Fischer, F. (2006). A framework to analyze argumentative knowledge construction in computer-supported collaborative learning. Computers \& Education, 46, 71-95.

Wilson, J. M., Straus, S. G., \& McEvily, B. (2006). All in due time: The development of trust in computer mediated and face-to-face teams. Organizational Behavior and Human Decision Processes, 99, 16-33.

Wood, D., Bruner, J., \& Ross, G. (1976). The role of tutoring in problem solving. Journal of Child Psychology and Psychiatry, 17, 89-100.

Zimmerman, B. J. (2002). Becoming a self-regulated learner: An overview. Theory into Practice, 42(2), 6470. 